\title{
Buoyed up and slowed down: speed limits for diving birds in shallow water
}

\author{
Emily L. C. Shepard ${ }^{1, *}$, Rory P. Wilson ${ }^{1}$, Agustina Gómez Laich ${ }^{2}$, Flavio Quintana ${ }^{2,3}$ \\ ${ }^{1}$ Department of Pure and Applied Ecology, Institute of Environmental Sustainability, Swansea University, Swansea SA2 8PP, UK \\ ${ }^{2}$ Centro Nacional Patagónico (CENPAT)-CONICET, (9120) Puerto Madryn, Chubut, Argentina \\ ${ }^{3}$ Wildlife Conservation Society, 2300 Southern Boulevard, New York, New York 10460, USA
}

\begin{abstract}
In air-breathing animals, the time and energy costs of each dive are primarily determined by depth-related upthrust, swim speed and temperature. While studies have previously investigated how animals should optimise their behaviour in relation to either upthrust or speed they have rarely been examined in tandem. We took overall dynamic body acceleration (ODBA) as a proxy for the mechanical power used during the bottom phases of dives of imperial shags Phalacrocorax atriceps, as these birds forage benthically, in order to define: (1) the minimum power required for swimming at depth and (2) how the use of power above this threshold varied with dive depth. Results showed that ODBA declined with increasing dive depth in a manner correlated with the reduction in upthrust, and that the use of power above that required for prey searching increased with increasing dive depth. This may constitute a response to depth-related patterns in prey availability. We present a model to investigate an alternative hypothesis that the ability of birds to produce burst speeds is also inversely related to the power required to counter buoyancy. Under the model assumptions, achievable burst speeds vary up to $0.7 \mathrm{~m} \mathrm{~s}^{-1}$ across dive depths from 5 to $60 \mathrm{~m}$. Ultimately, prey preferences cannot be separated from prey fields, but we suggest that this model may provide insight into the ability of air-breathing divers to pursue various prey types according to dive depth.
\end{abstract}

KEY WORDS: Swim speed - Diving bird - Accelerometry $\cdot$ Overall dynamic body acceleration · ODBA

\section{INTRODUCTION}

Air-breathing divers acquire oxygen at the water surface and their food at a spatially different site underwater and are thus under considerable selection pressure to modulate oxygen use judiciously during foraging. Assuming that such animals rely principally on aerobic respiration (e.g. Butler 2004), an individual's dive duration will be primarily limited by the rate of oxygen use, this itself being closely linked to the mechanical power used underwater (Boyd et al. 1995, Butler \& Jones 1997). In benthicforaging diving birds, power requirements for the descent and ascent phases of the dive are a remarkably constant function of dive depth (Watanuki et al. 2005, Wilson et al. 2006, Shepard et al. 2009, their
Fig. 1) because these costs relate primarily to the mechanical work associated with the displacement between the surface and the seabed. Thus the variance in energy used during the whole dive cycle is essentially determined by dive depth and the use of power in the bottom phase.

The mechanical power requirements in all phases of the dive are determined primarily by 2 different forces acting on the swimming body, those of upthrust and drag (Lovvorn et al. 1991, Wilson et al. 1992), as well as inertial work in acceleration. Since, in diving birds, body density (excluding air spaces) is similar to that of water (Wilson et al. 1992), the overall upthrust is primarily a function of the air contained in the plumage and respiratory spaces, which becomes compressed with increasing water depth according to Boyle's Law. 
This upthrust defines the minimum power requirements of any moment during a dive, as birds must produce a force equal to it in order to simply remain at a particular depth. These costs decline most rapidly in the first few metres of the water column (Wilson et al. 1992, Watanuki et al. 2003).

Power requirements above this minimum are determined by the bird's swim speed. In order to move forwards, a bird must produce enough power to overcome the drag, which increases as an accelerating function of speed (Kooyman \& Davis 1987, Lovvorn et al. 1999). High speeds, including those characteristic of prey pursuit, are therefore particularly energetically costly, and use of such speeds causes substantial depletion of oxygen reserves, compromising dive duration accordingly (Wilson et al. 2002a). Therefore, there is likely to be strong pressure for the conservative use of power during the dive, with animals selecting search speeds that will maximise their prey search time, increasing their speed only where, and as much as, necessary to pursue and capture prey items (Boyd et al. 1995, Wilson et al. 2002a). As air-breathing divers can catch multiple prey items in one dive (e.g. Wilson et al. $2002 \mathrm{~b}$ ), the allocation of resources to catching the first item has implications for the success of the remainder of the dive. Consequently, in pursuit-diving animals (sensu Ashmole \& Ashmole 1967), fine-scale changes in swim speed within the dive may provide insight into both prey availability (cf. Wilson et al. 2002a) and how predators manage oxygen budgets under different conditions.

We used a relatively new method to quantify the fine-scale changes in use of mechanical power during the dives of free-living imperial shags Phalacrocorax atriceps. These birds are benthic foragers and, consequently, the different phases of the dive are clearly separated according to function, with the descent and ascent phases representing travel and the bottom phase representing a combination of prey search, pursuit, capture and handling. Acceleration was recorded in imperial shags and used to derive the overall dynamic body acceleration (ODBA), a single, unified measure of body motion (Wilson et al. 2006). ODBA was used as a proxy for mechanical work, based on the principle that chemical energy is required to produce motion and motion requires mechanical work (A. Gleiss, R. P. Wilson, E. L. C. Shepard unpubl. data). This has been given credence by high correlation coefficients between ODBA and energy expenditure for 10 species during locomotion (Halsey et al. 2009) and, further, between ODBA and upthrust during the dive descents of imperial shags (Wilson et al. 2006). Our objectives were to: (1) define the minimum power requirements associated with prey searching in relation to dive depth (assuming that birds select the most efficient swim speed for search behaviour) and (2) examine how actual power use varied in relation to this minimum, in order to gain insight into the availability of prey types with dive depth.

\section{MATERIALS AND METHODS}

Data collection. Imperial shags were instrumented with daily diary (DD) units (Wilson et al. 2008a) to record acceleration values in 3 axes, hydrostatic pressure, beak opening angle (with inter-mandibular angle sensors [IMASEN], see below) and up to 10 other parameters, not considered here, with 22 bit resolution. Acceleration and pressure were recorded at frequencies of $6 \mathrm{~Hz}$ when DD units included an IMASEN and $9 \mathrm{~Hz}$ when they did not. The units were streamlined to minimise drag and had maximum dimensions of $70 \times$ $40 \times 10 \mathrm{~mm}$ and a maximum mass of $36 \mathrm{~g}$ in water and $68 \mathrm{~g}$ in air, representing no more than $2.5 \%$ of the bird's mean body mass (Svagelj \& Quintana 2007).

A total of 17 male imperial shags were equipped in the austral summers of 2005 to 2008 in colonies at Punta Léon $\left(43^{\circ} 04^{\prime} \mathrm{S}, 64^{\circ} 2^{\prime} \mathrm{W}\right)$ and Bahia Bustamante $\left(45^{\circ} 10^{\prime} \mathrm{S}, 66^{\circ} 30^{\prime} \mathrm{W}\right)$, Chubut, Argentina. All birds were brooding small chicks at the time of instrumentation. Birds were slowly removed from the nest using a custom-made crook and devices were attached to the lower back using Tesa tape (Wilson et al. 1997).

Of the 17 DD units deployed, 8 included IMASENs, which measure beak-opening angle and, thereby, prey capture events (Wilson et al. 2002b). In these units, a Hall sensor was connected to the main DD via a cable $(3 \times 420 \mathrm{~mm}$, diameter $\times$ length $)$. The Hall sensor was embedded in epoxy resin and secured in a saddle, which enabled it to fit snugly over the upper mandible, to which it was secured using 2-part epoxy adhesive (Poxipol) (Fig. 1a). This whole satellite unit had a mass of ca. $1.3 \mathrm{~g}$. A circular neodymium boron magnet $(3 \times 2 \mathrm{~mm})$ was then attached to the lower mandible below the Hall sensor using the same adhesive. In order to convert beak opening angle into degrees, the IMASEN was calibrated by holding the mandibles open on either side of a turned aluminium rod, which consisted of sections of known diameter, increasing from 5 to $25 \mathrm{~mm}$ in $2.5 \mathrm{~mm}$ intervals (Wilson et al. 2002b). By measuring the distance between the centre of the rod and the point of articulation of the mandible, beak opening angle could be converted into degrees using simple trigonometry. These values were then regressed against the Hall sensor output voltages recorded by the logger at the time of the calibration (see Wilson et al. 2002b for details). The cable was secured at intervals to the bird's neck using small strips of Tesa tape (cf. Wilson et al. 1997). The 


\section{a}

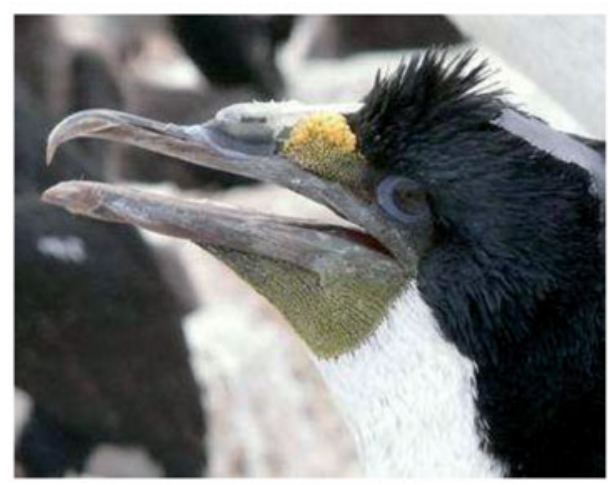

b

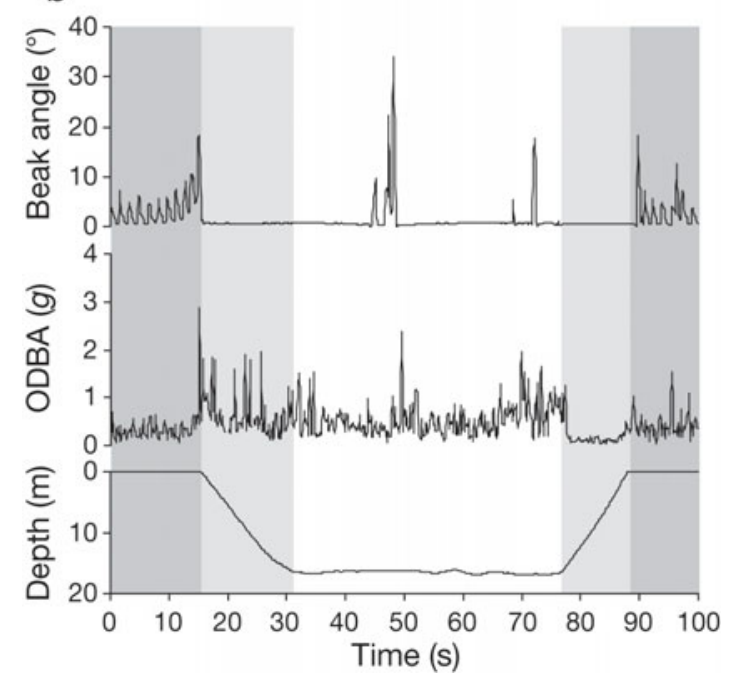

Fig. 1. Phalacrocorax atriceps. (a) Imperial shag instrumented with an inter-mandibular angle sensor unit to record (b) beak opening angle, given in relation to overall dynamic body acceleration (ODBA) and dive depth for a single dive. Periods at the surface are highlighted in dark grey (beak openings here relate to patterns of respiration in preparation for and response to energy use during the dive), and the dive descent and ascent are shaded in light grey. Beak opening events during the bottom phase (unshaded) represent prey capture attempts

whole process took a mean of 13.8 min (range $=12$ to $16 \mathrm{~min}$ ), in comparison to a mean of ca. 8 min for units without IMASEN.

Following instrumentation, birds were returned to the nest and left to forage for a single trip before the device was removed. Procedures were approved by ethics committees at Swansea University, UK, and the National Research Council of Argentina.

Data analysis. ODBA is a measure of body motion derived from measurements of acceleration made in all 3 spatial axes (Wilson et al. 2006). Raw acceleration values are comprised of a dynamic component and a static component. The latter was estimated by smoothing the data in each channel with a running mean over a period of $3 \mathrm{~s}$ (Shepard et al. 2008). The dynamic com- ponent was derived by subtracting the static values from the raw acceleration values in the same period. Dynamic values were made positive and summed from the 3 axes to give ODBA, which is given in units of gravitational force $(g)$. In order to account for variation in sampling frequency, acceleration data originally recorded at $9 \mathrm{~Hz}$ were thinned to $6 \mathrm{~Hz}$. The mechanical power used within the dive is alluded to by measurements of ODBA summed over second intervals (cf. Wilson et al. 2006, Fahlman et al. 2008, Green et al. 2009, Halsey et al. 2009).

Only dives that had a square-shaped depth profile were included in the analysis as these are likely to represent benthic foraging dives (as opposed to infrequent V-shaped dives that might arise from pelagic foraging). Dives were binned according to maximum depth as depth varied little in the bottom phase. The frequency of ODBA values within the bottom phase was calculated for 20 dives for each $5 \mathrm{~m}$ depth range from 15 to $55 \mathrm{~m}$, with the exception of dives with a maximum of 30 to $35 \mathrm{~m}$, which were under-represented in the data collected, with a total of 14 dives recorded across individuals and years.

In order to examine how ODBA was related to upthrust across dive depths, the upthrust was calculated for any given dive depth following Quintana et. al. (2007), assuming a body plumage air of $170 \mathrm{ml} \mathrm{kg}^{-1}$ (Gremillet et al. 2005), respiratory air of $160 \mathrm{ml} \mathrm{kg}{ }^{-1}$ (Lasiewski \& Calder 1971), body mass of $2.3 \mathrm{~kg}$ (Svagelj \& Quintana 2007) and a bird body density that is otherwise neutrally buoyant in seawater (Wilson et al. 1992). Analyses were performed in Microsoft Excel and using the custom-written software Snoop (G. Thomas, freeware).

To estimate the ODBA associated with prey searching (as distinct from prey pursuit and handling) ODBA was calculated for periods between beak opening events where several seconds of continuous swimming occurred $>3$ s following the previous beak opening and $>3 \mathrm{~s}$ prior to the next. These ODBA values were extracted for all square-shaped dives with IMASEN data. IMASEN beak angle data were considered to be indicative of prey capture attempts where beak opening events were $>2^{\circ}$ (cf. Wilson et al. 2002b). These were counted per bird in relation to the time spent during the bottom phase.

\section{RESULTS}

\section{Prey capture determined with IMASEN}

Of the 8 units that included IMASENs, only 3 gave usable data. The remainder either failed due to breakages in the cable or had extensive noise in the signal, 
rendering prey capture attempts unidentifiable, most likely the result of poor alignment of the magnet with the Hall sensor. The 3 successful IMASENs produced clear results, with distinct beak opening events along the bottom of the dive that sometimes coincided with an increase in ODBA (Fig. 1b). Overall, birds had 434 prey capture attempts with a mean frequency of one attempt per $17.4,8.4$ and $7.9 \mathrm{~s}$ of bottom time for the 3 birds, respectively. Analysis of 50 beak opening events showed that pursuits lasted for $1 \pm 0.5 \mathrm{~s}$ prior to attempted capture; using this, individual birds are estimated to have spent $88.2,87.4$ and $94 \%$ of the total bottom time searching and the remainder pursuing prey.

Within individuals, dives were performed in 1 to 3 main bouts, each with a restricted depth range; consequently, IMASEN data were not acquired across all dive depths (Fig. 2). Taking these limited data, the maximum gape angle of each beak opening event did not appear to increase with maximum dive depth (Fig. 2).

\section{ODBA as a function of dive depth}

ODBA values during the bottom phase of the dive varied in relation to dive depth in a number of ways. Mean ODBA s ${ }^{-1}$ decreased with increasing dive depth (Fig. 3a), as did the mean ODBA value per bottom phase, which was strongly correlated with the upthrust across dive depths (Fig. 3b).

The frequency distributions of ODBA values during the bottom phase were left-skewed for all dive depths and the skew became more pronounced as dive depth increased (Fig. 4). The skew could have arisen if, for instance, the main frequency peak was associated with travel and the higher ODBA values with prey pursuit and handling (cf. Fig. 1b). This appeared to be the case for deeper dives (40 to $55 \mathrm{~m}$ ), where ODBA values dur-

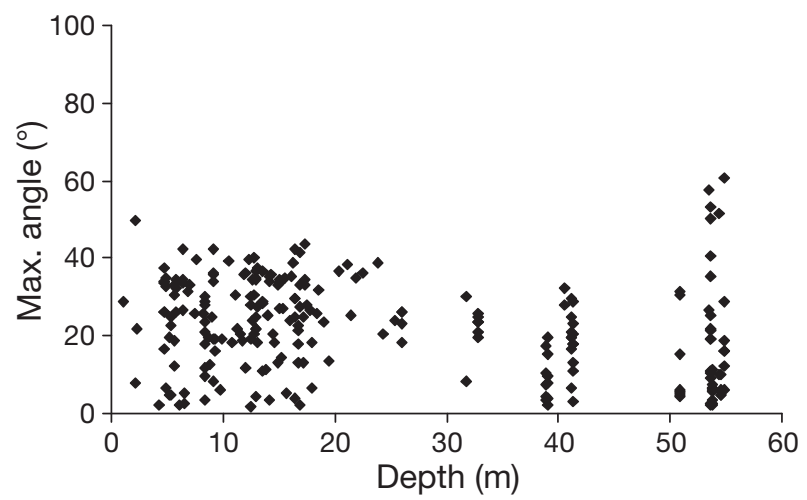

Fig. 2. Phalacrocorax atriceps. Maximum angle recorded during each beak opening event in relation to dive depth, where events are identified as openings $>2^{\circ}$
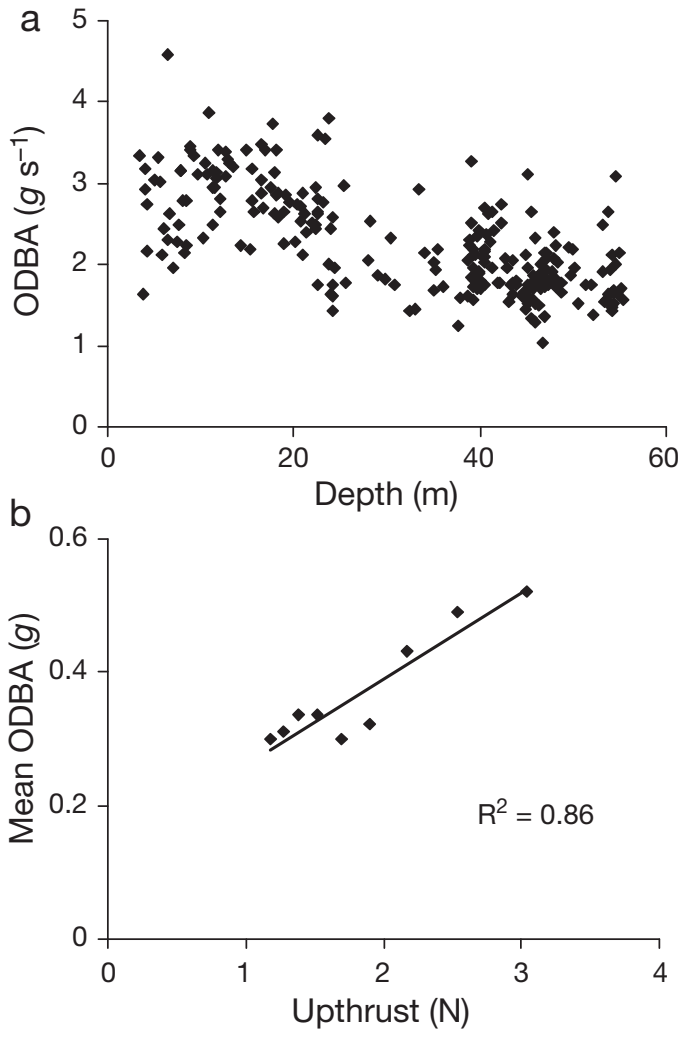

Fig. 3. Phalacrocorax atriceps. Overall dynamic body acceleration (ODBA) values in relation to maximum dive depth where ODBA is given as (a) the mean value per second for individual bottom phases $\left(y=-0.027 x+3.14, \mathrm{R}^{2}=0.47, \mathrm{df}=244\right.$, $F=212, \mathrm{p}<0.001)$ and (b) a grand mean of all ODBA values within $5 \mathrm{~m}$ depth bins and regressed against the upthrust calculated for birds at the given depth

ing searching (those between prey capture events) were lower than ODBA values across the bottom phase as a whole (Fig. 5) and in fact corresponded to the lowest $85 \%$ of ODBA values throughout the bottom phase.

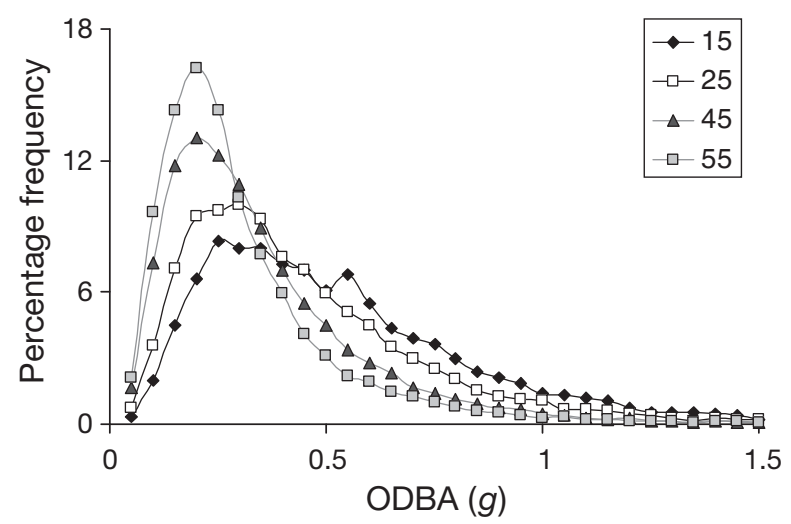

Fig. 4. Phalacrocorax atriceps. Percentage frequency of overall dynamic body acceleration (ODBA) values during the bottom phase of dives binned according to maximum dive depth, with bin widths of $5 \mathrm{~m}$ (see legend). Only 4 depth bins are shown for the purposes of clarity 

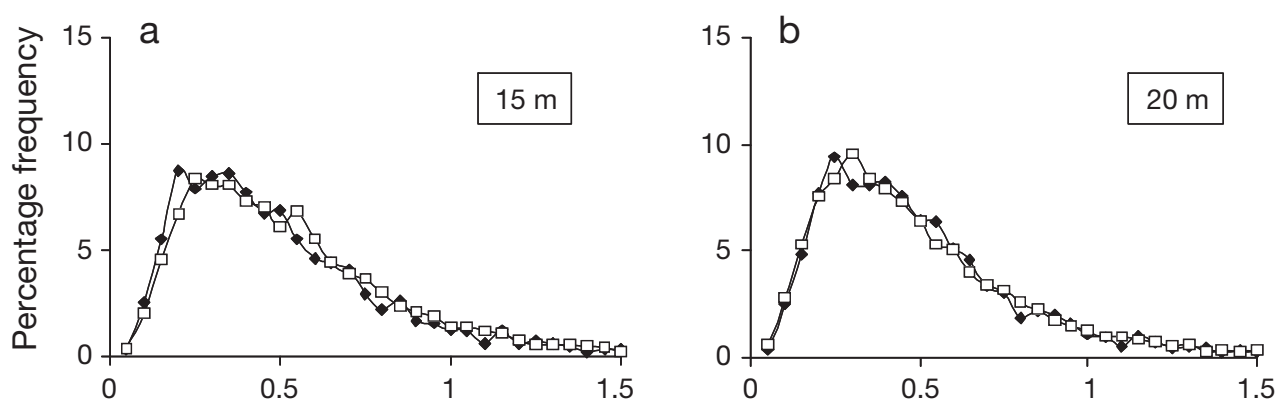

Fig. 5. Phalacrocorax atriceps. Percentage frequency of overall dynamic body acceleration (ODBA) values throughout the bottom phase (ㅁ) in relation to the percentage frequency of ODBA values taken between beak opening events ( $\bullet$ for dives binned to (a) $10-15 \mathrm{~m} \mathrm{(b)} 15-20 \mathrm{~m}$ (c) $40-45 \mathrm{~m}$ and (d) $50-55 \mathrm{~m}$
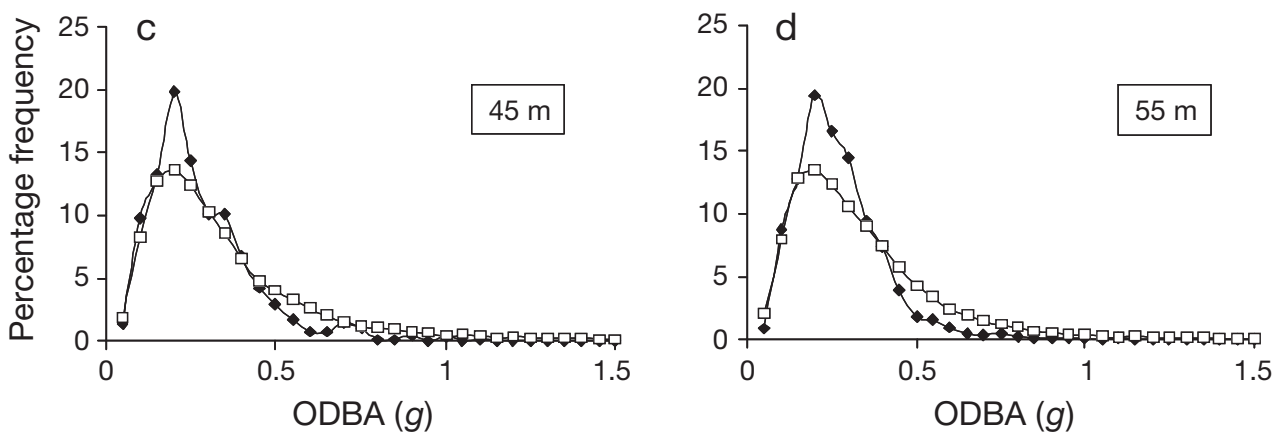

However, at shallow dive depths (10 to $20 \mathrm{~m}$ ) ODBA during searching was indistinguishable from values taken over the whole bottom phase (Fig. 5).

\section{DISCUSSION}

Overall, ODBA values during the bottom phase decreased with increasing dive depth in a manner that was correlated with the upthrust experienced by the birds (Fig. 3). This is consistent with previous findings (Wilson et al. 2006) and implies that upthrust (and, by proxy, dive depth) is likely to be the primary determinant of the mechanical power required during the bottom phase (see also Wilson et al. 2006, Shepard et al. 2009).

During deeper dives, ODBA values associated with prey searching (those calculated between prey capture events) were lower than those of the entire bottom phase (which included searching, pursuit, capture and handling of prey) (Fig. 5). This suggests that the prey types targeted during deep dives require pursuit speeds in excess of those used during prey searching, whereas prey targeted in shallower dives are caught and handled with a power output similar to that used for prey searching. This may be a response to depth-related changes in prey availability, namely an increase in prey density or prey size with dive depth (Lovvorn \& Jones 1991, Watanuki et al. 2003), causing an increase in the frequency or strength of pursuits, respectively (Macpherson \& Duarte 1991). Indeed, it has been suggested that depth-related patterns in prey availability are responsible for the dietary differences between males and females of several cormorant species (Kato et al. 1996, 2001, Bearhop et al. 2006), as females are generally smaller than males of the same species, perform more shallow dives and take smaller prey (Peters et al. 1998). We note that in the present study, maximum beak angle did not appear to increase with dive depth; however, the relationship between beak angle and prey size may be complicated by the handling requirements of various prey types. In fact this seems likely, as regurgitates from imperial shags at both study sites show that the shallow-diving females forage on smaller prey items than the deeper-diving males (F. Quintana unpubl. data).

The observed increase in bottom effort with dive depth could also arise if the ability of imperial shags to increase their swimming speed was contingent upon dive depth. Animals are subject to restrictions in the maximum power they can produce for both sustained locomotion and burst speeds (Wardle 1975, Bennett 1991). Therefore, when buoyancy-related costs are high, birds may have little metabolic scope to allocate to the production of pursuit speeds. The reverse is true for birds foraging at greater depths (up to the point where they approach neutral buoyancy). Here we present a simplistic model to explore how decreases in buoyancy might allow foraging cormorants to increase their prey-capture performance via increases in speed, before we consider the effect that this may have on cormorant foraging ecology as a function of depth. 


\section{Model construction}

We assumed that the maximum power available to the bird $\left(P_{\max }\right)$ is given by the maximum observed ODBA found per second underwater. This was taken as $11.0 \mathrm{~g} \mathrm{~s}^{-1}$, which was the mean maximum ODBA s${ }^{-1}$ across individuals (range $=8.3$ to $15.4 \mathrm{~g} \mathrm{~s}^{-1}$ ). The relationship between ODBA and depth for cormorants swimming along the seabed was estimated using values of ODBA taken between beak opening events. As these data were only available for dives from 10 to 20 and 40 to $55 \mathrm{~m}$, values of ODBA s ${ }^{-1}$ were plotted for these depths, and the following trendline was fitted between the data clusters:

$$
\mathrm{ODBA}=-1.25 \ln (z)+6.29
$$

where $z$ is depth $(\mathrm{m})$. A logarithmic function was selected following Wilson et al. (1992), where the theoretical relationship between energy expended and dive depth in cormorants followed a logarithmic decay. Thus the available power for an underwater pursuit $\left(\mathrm{ODBA}_{\text {speed }}\right)$ is given by:

$$
\mathrm{ODBA}_{\text {speed }}=P_{\max }-[-1.25 \ln (z)+6.29]
$$

Since ODBA scales linearly with metabolic power for movement (Wilson et al. 2006, Halsey et al. 2008, Green et al. 2009, Halsey et al. 2009), it follows that, if the relationship between metabolic power $(P)$ and speed for cormorants (we use the relationship for Phalacrocorax carbo since none is available for $P$. atriceps) is given by:

$$
P=3.6 S^{3}-12.2 S^{2}+21.5 S+k_{1}
$$

where $S$ is the swim speed $\left(\mathrm{m} \mathrm{s}^{-1}\right)$ and $k_{1}$ is a constant representing the energy consumption when resting at the water surface (Schmid et al. 1995), then ODBA as a function of speed is given by:

$$
\mathrm{ODBA}_{\text {speed }}=k_{2} P
$$

where $k_{2}$ is a constant derived as follows. The relationship between ODBA and $P$ can be found by regressing ODBA against the power required to swim at a given speed (derived from Eq. 3), where a value of $0.1 \mathrm{~g}$ is used as the resting value of ODBA (Shepard et al. 2009). As swim speed was not available from the present study, it was taken as the mean bottom swim speed for 4 cormorant species, with a value of $0.85 \mathrm{~m} \mathrm{~s}^{-1}$ (Wilson \& Wilson 1988, Ropert-Coudert et al. 2006). We take the ODBA associated with this speed as that derived for searching along the seabed at $15 \mathrm{~m}$ (Eq. 1), as this was the depth range at which speed during the bottom phase was measured for 4 cormorant species by Wilson \& Wilson (1988). Using this conversion, ODBA is related to $P$ via:

$$
\mathrm{ODBA}=0.24 P+0.1
$$

If we calculate the power required for a range of swim speeds (following Eq. 3) and convert this to ODBA (using Eq. 5) then speed can be derived graphically as a function of available ODBA, which is described by:

$$
\ln (S)=2.02-3.31 / \text { ODBA }_{\text {speed }}{ }^{0.5}
$$

Thus the maximum speed available to imperial shags at any depth can be derived using Eqs. (2) \& (6) (Fig. 6). This approach indicates that depth may account for a difference of $0.5 \mathrm{~m} \mathrm{~s}^{-1}$ in attainable speed across depths from 5 to $60 \mathrm{~m}$, with maximum speeds ranging from 2.1 to $2.6 \mathrm{~m} \mathrm{~s}^{-1}$ above search speed (Fig. 6). If the ODBA ceiling (corresponding to a maximum power) is decreased, the difference in maximum speed increases (Fig. 6); using a value of $8 \mathrm{~g}$ for $P_{\max }$ (the lowest value of $P_{\max }$ in the data), the difference in maximum speed across dive depths becomes $0.7 \mathrm{~m} \mathrm{~s}^{-1}$, and if $P_{\max }=15 \mathrm{~g}$ (the highest $P_{\max }$ founding the data), the difference in maximum speed varies by $0.3 \mathrm{~m} \mathrm{~s}^{-1}$ (Fig. 6).

\section{Model criticism}

This is a simplistic attempt to show how decreasing power costs with increasing depth may relate to greater power being available for pursuit speed. The model assumes that once the costs of countering buoyancy have been accounted for, the power required to produce any further speed remains the same across dive depths. This may not be valid if, for example, energy savings from swimming patterns such as the burst-and-glide gait (Ribak et al. 2005) vary with dive depth. Indeed this is quite likely, given

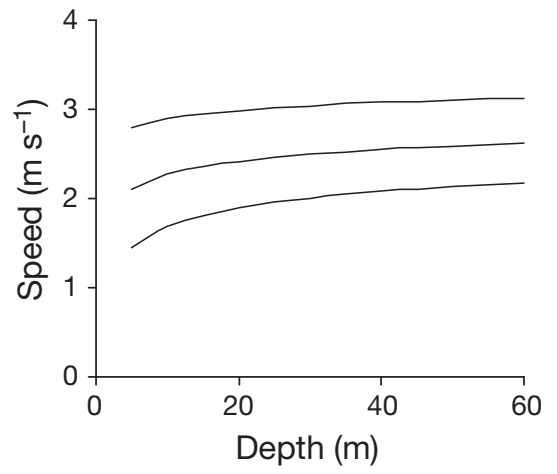

Fig. 6. Phalacrocorax atriceps. Theoretical swim speeds that birds are able to achieve above their search speed $\left(0.85 \mathrm{~m} \mathrm{~s}^{-1}\right)$, assuming that there is a limit to the instantaneous power (here overall dynamic body acceleration [ODBA]) birds can produce. Ceiling values were set at $11 \mathrm{~g}$, as the grand mean of the maximum ODBA values found across individuals (upper line), $8 g$ (middle line) and $5 g$ (lower line) 
that the burst-and-glide gait appears to provide energy savings during swimming at elevated body angles, and body angle varies with dive depth (Watanuki et al. 2005). Data on swim speed in relation to ODBA and dive depth could provide further insight here. It is also worth noting that the power costs above those estimated for prey searching were derived using the relationship between power and swim speed (Eq. 3), where swim speed increases from zero. While this is not strictly the case for imperial shags (which are increasing their speed from an estimated $0.85 \mathrm{~m} \mathrm{~s}^{-1}$ ), we consider that this is unlikely to be a large source of error as the metabolic power increases slowly and relatively constantly for swim speeds $\leq 2 \mathrm{~m} \mathrm{~s}^{-1}$ (Schmid et al. 1995).

The model also assumes that the search speed remains constant with depth. An assessment of swim speed in 4 species of cormorant revealed that speed during the bottom phase only varied with depth in the white-breasted cormorant Phalacrocorax carbo lucidus (Wilson \& Wilson 1988). In addition, the correlation between ODBA and upthrust (Fig. 3b) implies that search speed in the bottom phase either varies linearly or is constant with depth (assuming that ODBA scales linearly with metabolic rate, Wilson et al. 2006, Fahlman et al. 2008, Halsey et al. 2009). If swim speed increased with dive depth (as in P. carbo lucidus), then the power, or ODBA, required to produce a given speed with increasing dive depth would be underestimated, as would the depth-related increase in achievable pursuit speeds.

\section{Implications of model outcomes}

While our model predicts that the difference in estimated maximum speeds with depth is relatively small, it may still be highly relevant in determining which size prey birds may catch, as burst speeds in fish are related to body size (Wardle 1975). Furthermore, even a difference of $0.5 \mathrm{~m} \mathrm{~s}^{-1}$ represents a substantial part of the range of burst speeds (ca. 0.7 to $5.5 \mathrm{~m} \mathrm{~s}^{-1}$ ) for species commonly preyed upon by Phalocrocorax carbo in Europe (Ropert-Coudert et al. 2006).

Importantly, the large power requirements needed for high pursuit speeds make it sometimes more appropriate to take longer to pursue prey at lower speeds (Wilson et al. 2002a). The variable metabolic costs of counteracting buoyancy have profound consequences for pursuit speed even when the birds are not operating at their metabolic ceiling. For example, according to our formulation, the difference in power use between an imperial shag pursuing prey at any speed at 5 or $60 \mathrm{~m}$ is $10.4 \mathrm{~W}$. If birds adopt pursuit speeds according to a restricted power allocation, however, the

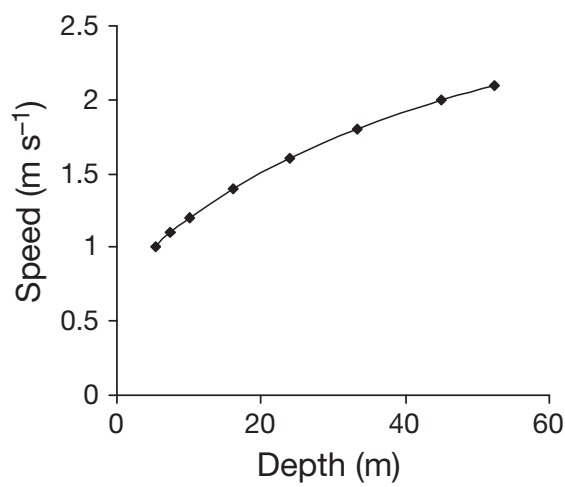

Fig. 7. Phalacrocorax atriceps. Predicted swim speed attainable with a power output of $20 \mathrm{~W}$ across dive depths

speeds attainable for pursuit vary considerably. For example, if a maximum of $20 \mathrm{~W}$ is allocated for a pursuit, this could generate a horizontal speed of $1.1 \mathrm{~m} \mathrm{~s}^{-1}$ when foraging at $5 \mathrm{~m}$ depth, while the same bird foraging at $60 \mathrm{~m}$ depth could travel at $2.1 \mathrm{~m} \mathrm{~s}^{-1}$ (Fig. 7). As a result, the costs of a pursuit and consequences for the remaining time and power available will vary with dive depth and, therefore, so will the net energetic gain per prey item. However, we note that the depthrelated trends in diet recorded for many species of cormorants (e.g. Kato et al. 2001, Bearhop et al. 2006), will presumably reflect a combined response to the variable costs of pursuing different prey types and sizes and bathymetric trends in prey availability (e.g. Macpherson \& Duarte 1991).

Given that most diving birds are highly buoyant compared to marine mammals or reptiles, the potential for them to be limited in the power they can invest in speed for pursuits at shallow depths has far-reaching implications. For example, speed restrictions would increase with the buoyancy of the species in question, those more buoyant being particularly confined to low swim speeds in shallow water. Indeed, the particularly high volumes of air in the plumage of certain diving bird groups such as auks might not only preclude them from exploiting shallow depths because their energy expenditure is so high (Wilson et al. 1992), but also because at such depths their available power does not allow them to pursue prey at appropriate speeds. This may help explain, for example, why auks dive so deeply for their body size (Watanuki \& Burger 1999) and why other birds such as diving ducks, which dive relatively shallowly, are either herbivorous or feed on sedentary prey. Ultimately though, the precise manner in which air for insulation (which modulates heat loss and power production to counteract it, Wilson et al. 2008b) affects power use and thus power available for speed as a function of depth is likely to be complex. However, it is clear that, 
given that the allocation of power to speed can be a function of depth, the appropriate pursuit (or not) strategy for diving birds will depend on the extent to which a pursuit compromises oxygen stores (and therefore bottom duration) and how this equates with the encounter rate of prey of varying sizes and escape speeds.

Acknowledgements. E.L.C.S. was funded by a NERC studentship (award no. NER/S/A/2005/13416A). Device development was supported by a Rolex Award for Enterprise, awarded to R.P.W. We also thank the Organismo Provincial de Turismo, Chubut, Argentina, for the permits to work in Punta Leon and the Centro Patagónico (Conicet) for institutional support. We are also grateful to the Wildlife Conservation Society and National Geographic for funding awarded to F.Q. and R.P.W., respectively, for fieldwork. We thank 4 anonymous reviewers, whose comments substantially improved the manuscript.

\section{LITERATURE CITED}

Ashmole NP, Ashmole J (1967) Comparative feeding ecology of seabirds of a tropical oceanic island. Bull Peabody Mus Nat Hist 24:1-131

Bearhop S, Phillips RA, McGill R, Cherel Y, Dawson DA, Croxall JP (2006) Stable isotopes indicate sex-specific and long-term individual foraging specialisation in diving seabirds. Mar Ecol Prog Ser 311:157-164

Bennett AF (1991) The evolution of activity capacity. J Exp Biol 160:1-23

Boyd IL, Reid K, Bevan RM (1995) Swimming speed and allocation of time during the dive cycle in Antarctic fur seals. Anim Behav 50:769-784

Butler PJ (2004) Metabolic regulation in diving birds and mammals. Respir Physiol Neurobiol 141:297-315

Butler PJ, Jones DR (1997) Physiology of diving of birds and mammals. Physiol Rev 77:837-899

Fahlman A, Wilson RP, Svärd C, Rosen DAS, Trites AW (2008) Activity and diving metabolism correlate in Steller sea lion Eumetopias jubatus. Aquat Biol 2:75-84

> Green JA, Halsey LG, Wilson RP, Frappell PB (2009) Estimating energy expenditure of animals using the accelerometry technique: activity, inactivity and comparison with the heart-rate technique. J Exp Biol 212:471-482

Gremillet D, Chauvin C, Wilson RP, Le Maho Y, Wanless S (2005) Unusual feather structure allows partial plumage wettability in diving great cormorants Phalacrocorax carbo. J Avian Biol 36:57-63

Halsey LG, Shepard ELC, Hulston CJ, Venables MC, White CR, Jeukendrup AE, Wilson RP (2008) Acceleration versus heart rate for estimating energy expenditure and speed during locomotion in animals: tests with an easy model species, Homo sapiens. Zoology 111:231-241

Halsey LG, Shepard ELC, Gómez Laich A, Quintana F, Green JA, Wilson RP (2009) The relationship between oxygen consumption and body motion in a range of species. Comp Biochem Physiol A 152:197-202

Kato A, Naito Y, Nishiumi I (1996) Sexual differences in diet of king cormorants and Macquarie island. Polar Biol 16: 75-77

Kato A, Watanuki Y, Naito Y (2001) Foraging and breeding performance of Japanese cormorants in relation to prey type. Ecol Res 16:745-758

Kooyman GL, Davis RW (1987) Diving behavior and performance, with special reference to penguins. In: Croxall JP (ed) Seabirds: feeding ecology and role in marine ecosystems. Cambridge University Press, Cambridge, p 63-75

Lasiewski RC, Calder WA (1971) A preliminary allometric analysis of respiratory variables in resting birds. Respir Physiol 11:152-166

> Lovvorn JR, Jones DR (1991) Body mass, volume, and buoyancy of some aquatic birds, and their relation to locomotor strategies. Can J Zool 69:2888-2892

Lovvorn JR, Jones DR, Blake RW (1991) Mechanics of underwater locomotion in diving ducks: drag, buoyancy and acceleration in a size gradient of species. J Exp Biol 159:89-108

> Lovvorn JR, Croll DA, Liggins GA (1999) Mechanical versus physiological determinants of swimming speeds in diving Brunnich's guillemots. J Exp Biol 202:1741-1752

- Macpherson E, Duarte CM (1991) Bathymetric trends in demersal fish size: Is there a general relationship? Mar Ecol Prog Ser 71:103-112

> Peters G, Wilson RP, Scolaro JA, Laurenti S, Upton J, Galleli H (1998) The diving behavior of Magellanic penguins at Punta Norte, Peninsula Valdes, Argentina. Colon Waterbirds 21:1-10

Quintana F, Wilson RP, Yorio P (2007) Dive depth and plumage air in wettable birds: the extraordinary case of the imperial cormorant. Mar Ecol Prog Ser 334:299-310

> Ribak G, Weihs D, Arad Z (2005) Submerged swimming of the great cormorant Phalacrocorax carbo sinensis is a variant of the burst-and-glide gait. J Exp Biol 208:3835-3849

Ropert-Coudert Y, Gremillet D, Kato A (2006) Swim speeds of free-ranging great cormorants. Mar Biol 149:415-422

Schmid D, Gremillet DJH, Culik BM (1995) Energetics of underwater swimming in the great cormorant (Phalacrocorax carbo sinensis). Mar Biol 123:875-881

Shepard ELC, Wilson RP, Halsey LG, Quintana F and others (2008) Deviation of body motion via appropriate smoothing of acceleration data Aquat Biol 4:235-241

Shepard ELC, Wilson RP, Quintana F, Gómez Laich A, Forman D (2009) Pushed for time or saving on fuel: fine-scale energy budgets shed light on currencies in a diving bird. Proc R Soc Lond B 276:3149-3155

Svagelj W, Quintana F (2007) Sexual size dimorphism and sex determination by morphometric measurements in breeding imperial shags (Phalacrocorax atriceps). Waterbirds 30:97-102

- Wardle CS (1975) Limits of fish swimming speed. Nature 255:725-727

- Watanuki Y, Burger AE (1999) Body mass and dive duration in alcids and penguins. Can J Zool 77:1838-1842

> Watanuki Y, Niizuma Y, Gabrielsen GW, Sato K, Naito Y (2003) Stroke and glide of wing-propelled divers: deep diving seabirds adjust surge frequency to buoyancy change with depth. Proc R Soc Lond B 270:483-488

Watanuki Y, Takahashi A, Daunt F, Wanless S, Harris M, Sato K, Naito Y (2005) Regulation of stroke and glide in a footpropelled avian diver. J Exp Biol 208:2207-2216

Wilson RP, Wilson MPT (1988) Foraging behavior in four sympatric cormorants. J Anim Ecol 57:943-955

Wilson RP, Hustler K, Ryan PG, Burger AE, Nöldecke EC (1992) Diving birds in cold water: Do Archimedes and Boyle determine energetic costs? Am Nat 140:179-200

Wilson RP, Putz K, Peters G, Culik B, Scolaro JA, Charrassin JB, Ropert-Coudert Y (1997) Long-term attachment of transmitting and recording devices to penguins and other seabirds. Wildl Soc Bull 25:101-106 
Wilson RP, Ropert-Coudert Y, Kato A (2002a) Rush and grab strategies in foraging marine endotherms: the case for haste in penguins. Anim Behav 63:85-95

Wilson RP, Steinfurth A, Ropert-Coudert Y, Kato A, Kurita M (2002b) Lip-reading in remote subjects: an attempt to quantify and separate ingestion, breathing and vocalisation in free-living animals using penguins as a model. Mar Biol 140:17-27

- Wilson RP, White CR, Quintana F, Halsey LG, Liebsch N, Martin GR, Butler PJ (2006) Moving towards acceleration for

Submitted: August 5, 2009; Accepted: February 10, 2010 estimates of activity-specific metabolic rate in free-living animals: the case of the cormorant. J Anim Ecol 75: 1081-1090

Wilson RP, Shepard ELC, Liebsch N (2008a) Prying into intimate details of animal lives: use of a daily diary on animals. Endang Species Res 4:123-137

Wilson RP, Vargas FH, Steinfurth A, Riordan P, Ropert-Coudert Y, Macdonald DW (2008b) What grounds some birds for life? Movement and diving in the sexually dimorphic Galapagos cormorant. Ecol Monogr 78:633-652

Proofs received from author(s): March 2, 2010 